\title{
HUMANISM IN MEDICINE
}

\section{Kultaj Kaleka}

Medical Resident Internal Medicine-Psychiatry, University of Kentucky, Lexington, Kentucky, USA

kultaj.kaleka@uky.edu

\section{ABSTRACT}

The piece is an essay or reflection on the importance of humanism in medicine. The author encourages clinicians, first and foremost, to consider their relationship with patients from the vantage point of a shared humanity. This view allows for a better understanding of patients' needs and ensures patient-centered care.

KEYWORDS: Humanism, Medicine, Patients

have, for some time, harbored a wariness of words, concepts, and practices that end with "-ism." Superficially, "-ism", is a simple word-forming element. It comes from the Greek "-ismos" and serves an important function in the English language, signifying the practice or teaching of phenomenon. However, in our contemporary context with a drive to intellectualize and codify everything, "-ism" creates a certain mystique and complexity around simple concepts. It makes what is easy and simple in practice, esoteric. Being human or placing the interests and values of humans above all, does not need to be an "-ism."

Humanism is nowhere near as complex of a construct as capitalism, communism, socialism, colloquialism, etc. For the practice of humanism, no heavy leather-bound texts need be consulted or revered; nor is there a need for a revolution or purchase of stock. All being human requires is comprehension of, and reflection on, the truth that the other individuals are almost your mirror image. Just as you feel hunger, pain, cold, 
warmth, love, sadness, anger, confusion, and illness, so do others. Similarly, they too try their best to alleviate pain and cherish moments of compassion and happiness. As human(s), comprehending this truth, it behooves us to act in the best interest of other humans. In my strong opinion, humanism is the worthiest and most profound of all the "isms". Here, in support of this opinion, I relate a recent experience where my attending physician and I acted as human(s) and intervened to engage compassionately and respectfully with a vulnerable patient.

Through my chart review and prior conversation with my attending, I knew that Mr. P was an elderly patient with lung cancer. He had a poor prognosis, refused palliative care, and wanted to die at home. The only reason for his visit was a renewal of his COPD medication. Proudly independent, he lived by himself in an isolated rural area. While being his own decision maker, he was supported by a loving and caring family that regularly checked on him. His son, a busy firefighter and primary support, helped Mr. P with most instrumental and some daily activities of living.

Before meeting patients, I always struggle with a thought kaleidoscope. In addition to considering their reasons for the visit and related considerations (medications, differential diagnosis, etc.), I try to imagine how my patients live their day-to-day life: the kind of work they do, the people that are important to them, the struggles and barriers they experience. As someone with prior experience caring for the geriatric population, I wondered about Mr. P's ambulation, his diet, his gait, his cognitive status, the structure of his day, and his emotions in relation to his cancer. My short rumination spent trying to picture Mr. $P$ in his own context and considering questions that would help me understand the same, ended as I spotted an elderly man with a cane and his presumed (similar in appearance) son sitting adjacent to one another in the lobby.

At first glance, Mr. P had a somewhat bionic appearance. His hand loosely grasped a metallic cane, an artificial but steady limb to compensate for the inevitable infirmity brought by time. A small oxygen machine was slung over his shoulder. His oxygen tubing had been reinforced, taped to his body, at multiple sites: at his neck, just before it bifurcated, with loops taped behind both ears. One look revealed that the tape had been recycled. It had had been detached and reapplied to Mr. P's body many times. Despite the ardor and care in application, the tubing seemed to have had a mind of its own. Yet, ironically, the nasal prongs were still in place. The apparatus, patched and clumsy though it was, was sustaining the very organ that had allowed him to cherish life but would soon take him to the final resting stop in his life's journey.

Mr. P lit up and smiled warmly as I introduced myself as a medical student. I joked that his firm handshake indicated he couldn't be older than forty-five. I deemed it too soon to talk about, and clearly inappropriate to comment on, his long fingernails and the stains on his shirt. His son's face told a tale of fatigue, I noticed bags under his eyes and a worn face as I acknowledged him. I explained my purpose and role to them. They both agreed to allow me to assess him. As I ushered them into the clinic and towards the examination room, I mentally thanked them and all patients for their compassion for, and trust in, students. 
Mr. P shuffled into the examining room, taking small, slow steps towards a seat. I asked after how he was doing. Did he have any health concerns, or any needs? His responses, summarized, implied that he did not have any concerns or problems that he was worried about or needed to be addressed. He ate cereal and toast with coffee most days, watching TV as he did so. His son visited him once every two days, bringing dinner with him. He resolutely, as I had been previously told by the attending, did not want to talk about his cancer or palliative care. To my additional directed questions, he responded by relating a previous or current health problem, and how it had already been addressed perfectly by the attending. He often ended answering questions with some variation of how he no longer had any problems. As an example, while answering my question about any instances of shortness of breath he replied, "No, I got no shortness of breath now. This machine, the doc got it set up for me. The medical supply guy gets the oxygen to me. I got no trouble with it now." Talking to him, I sensed that he did not want to be a bother. Like others who cherish and pride their independence and self-reliance, he did not want to appear needy or dependent on anyone.

Proceeding to the physical, I conducted a comprehensive but unnecessarily exhaustive examination of Mr. $P$. With the innocence, eagerness, excitement and vigor, that can only be possessed by a novice, I subjected Mr. P to tests like a circus ringmaster. Full neurological, cardiovascular, respiratory, and gastrointestinal examination were undertaken. Not surprisingly, I saw only what I would have expected from a review of his chart: disease progression There were audible wheezing and a cough, consolidation to the right lower lung base as well as reduced grip strength and general muscle atrophy. Mr. P wanted nothing to be done about any of these findings. Frustrated, not being able to add anything of value to Mr. P's care, I calmed myself. This wasn't about me. Mr. P was here for a refill of his medications. Mr. P, the patient around whom care and this interaction was centered, did not expect anything more from this encounter.

Considering his point of view, I changed my approach. I tried again to imagine Mr. P in his own context. I wanted him to feel comfortable, not a burden, but an active partner in his own care. I wanted him, his perspective, his own identified needs to be seen and addressed. As I took off his shoes and socks to palpate his pulses, I noticed long toenails with dirt underneath them. I did not comment on them in the moment but waited until I had fully examined himself using my new lens. Finally, I sat back and addressed both Mr. P and his son. I stated, "Mr. P, I noticed you shuffling when you came in the room. You were using your cane, but still shuffling. If I am not wrong, if you are shuffling here, you were likely also shuffling at home. I think your toenails might be bothering you, can you reach your toes?"

Mr. P looked at me, then his son, and then back at me and replied, "They do hurt, I can't reach them. I asked him to cut them the other day, he don't got the time. I haven't showered in about two weeks either, or had my laundry done." The son, embarrassed, immediately apologized to Mr. P and explained how his busy schedule in the past month had been taxing, tiring, and the reason why he didn't have time to attend 
more diligently to Mr. P. I sat silently, an outsider to their family context, listening and respectfully waiting until the conversation was done. There was something that did bother Mr. P, and I had gained just enough trust for him to state it. His active medical issues were under control, he had understood and made his peace with his diagnosis. Nonetheless, his quality of life was affected, and his independence was compromised. Just like the cane that supported his gait and the oxygen machine that helped him breathe, something had to be done to continue to help him live his life the way he wanted to. Having gleaned as much as I could, I informed them that if there was nothing else they would like to share, I would go report to the attending and return with a plan.

I presented Mr. P to my attending, highlighting the issues as I saw them. His nails needed to be cut, caregiver burnout and support needed to be discussed. With my attending's full support, we went back into the room with clippers and sterile scissors. With Mr. P's grateful consent, we clipped his nails. Additionally, we spoke to Mr. P and his son, trying to negotiate a plan where he could get help with a shower and laundry in a more regular fashion. Without blaming his son, and with his support, we identified Mr. P's daughter and grandson as additional caregivers who could support Mr. P. A plan was made to involve them in Mr. P's care. As my attending signed the order for Mr. P's medication refill, Mr. P thanked us profusely, specifically remarking on how he'd never before had a doctor trim his toenails.

I reflect on this interaction often, especially Mr. P's remarks regarding his toenails being trimmed. As physicians and medical students, our medical knowledge and lens dominates our interactions with patients. Although important, this approach leads to an inherent bias. We sometimes overlook what patients really want or fail to identify their concerns. We assume that what we perceive to be important is what the patient would or should like addressed, a form of paternalism. Yet, if we step back and view ourselves as human beings interacting with other humans, our considerations may change. We begin to see the patient's perspective; this, in turn enables us to better understand and help them. Such is the power of humanism, shedding away preconceived notions, viewing and accepting patients for who they are, through compassion. 